\title{
Postoperative Hypothermia in Surgical Patients at Azadi Teaching Hospital
}

\author{
Anas Amer Mohammad ${ }^{1}$, Mehvan Jameel Ahmed ${ }^{2}$,

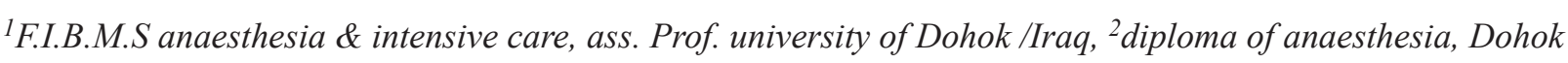 \\ medical director/Iraq.
}

\begin{abstract}
Introduction: The sensation to cold, shake occurrence and shivering are events that are commonly developed following general anesthesia administration postoperatively. Hypothermia has been considered as the most frequent outcome of surgery underwent by anesthesia. Inadvertent hypothermia has been taken into account as common side effect in the postoperative period immediately and it is related to wide impairments and anomalies of different body organs. Concentration on predictive factors of hypothermia would be important to reduce the incidence rate and correct preventable unnecessary risks for patients in the health settings following surgical operations. The aim of study is to assess the magnitude and associated factors of postoperative hypothermia recovery room in patients underwent general anesthesia. Methods: A hospitalbased prospective cross-sectional study was conducted on200patients with different age groups of both genders who underwent a scheduled non-cardiac surgery and general anesthesia consecutively during the period between the October $1^{\text {st }}$ and the November ${ }^{\text {st }} 2016$. Results: The study revealed that the overall core hypothermia in the study sample was $31 \%$. The study showed that the post-operative temperatures decreased statistically significantly in all study patients and separately in adults, children, males, or females $\mathrm{P}<0.001$. The study also revealed that the operation duration $(\mathrm{p}=0.045)$ and pre-operative temperature $\mathrm{P}<0.001$ were predictors of post-operative hypothermia in study sample. Conclusions: The incidence of hypothermia among study sample was not so high. A significant reduction in core body temperature of patients between pre and post-operation times was found. Those patients with longer operation duration, lower room temperature, and lower pre-operative temperature were at more risk of post-operative hypothermia.
\end{abstract}

Keywords: core temperature, hypothermia, anesthesia, post-operation.

\section{Introduction}

The sensation of patients to cold, shake occurrence and shivering are events that are commonly developed following general anesthesia administration postoperatively. Hypothermia has been considered as the most frequent outcome of surgery underwent by anesthesia. A highly evolved characteristics of mammals and birds are called homothermous assist body in regulating and maintaining the internal body temperature close to constant and largely independent on the surrounding environment temperature The

\section{Corresponding Author:}

Anas Amer Mohammad ${ }^{1}$

E-mail:dr.anasajam@Yahoo.com patients undergo regional or general anesthetic inducing changes in regulation of body health mechanisms together with exposure to cold in the operating room or environment of dental surgery take part in hypothermia ${ }^{1}$.Normothermia or normal body temperature is defined when the core body temperature has the range 36.5$37.5 \pm 0.5^{\circ} \mathrm{C}$. Hypothermia is defined as any core body temperature below1C in "Homothermous". Therefore, a core body temperature less than $36^{\circ} \mathrm{C}$ is considered as hypothermia ${ }^{2}$.The temperature range $32^{\circ} \mathrm{C}-36^{\circ} \mathrm{C}$ is considered as mild, $28-32^{\circ} \mathrm{C}$ as moderate, and below $28^{0} \mathrm{C}$ as severe hypothermia ${ }^{3,4}$.Some impairments resulted from hypothermia are reduction in the release of oxygen to the tissues 5, myocardial contractility, peripheral vasoconstriction ${ }^{6}$, mismatch of ventilationperfusion, blood viscosity increase, and left shift in the 
curve of oxyhemoglobin-dissociation ${ }^{7}$ Moreover, the hypothermia is responsible for reduction in the function of platelets ${ }^{8}$ and decrease in coagulation cascade activation 9 Concentration on predictive factors of hypothermia would be important to reduce the incidence rate and correct preventable unnecessary risks to patients in health settings following surgical operations. Therefore, the normal body temperature will be helpful in the reduction of hospital stay, infection of surgical site, blood transfusions postoperatively, pressure ulcers, disconformity and mortality ${ }^{2}$. The aim of this study is to assess the magnitude and associated factors of postoperative hypothermia at recovery room in patients underwent general anesthesia in Azadi Teaching Hospital.

\section{Material and Method}

Cross-sectional study was conducted in Azadi Teaching Hospital and included 200 patients with different ages groups of both gender who underwent a scheduled non-cardiac surgery and general anesthesia consecutively, a pre-designed questionnaire included name, sex, age, ASA physical status, operation duration, operation room temperature, pre-operative core temperature, post-operative core temperature, and administered intravenous fluids amount in the time of anesthesia. The physical examination was conducted for all patients in order to exclude those patients with fever, sepsis, and ear infection, patients with thermos- regulation abnormalities, and those with hypothyroidism or hyperthyroidism history from the study. In addition, the patients were treated under local anesthesia were not included in the study as well. The core temperature (Tc) of each patient was measured using infrared tympanic membrane thermometer (ThermosScan ${ }^{\circledR}$ Type 6014 Pro 3000 Welch Allyn Medical Products). the tympanic membrane and hypothalamus have the same arterial blood supply arising from the carotid artery, so the membrane directly reflects core temperature ${ }^{10}$. The measurement of tympanic membrane temperature was performed before surgery commencement and on the arrival of the patient at the recovery room. The ear pinna was softly pulled backwards and the thermometer was insulated into the external auditory meatus, turned and directed towards the patient eyes. According to the manufacturer's instructions, the probe of the thermometer remained inside the ear patient for 1 to 2 seconds in that position to hear a beep sound of the device. A second measurement of the tympanic temperature was performed after two minutes to avoid the temperature difference of the device and the researcher error measurement and their average considered as the result. The protocols of the manufacturer were strictly followed during the entire study period ${ }^{11}$. Statistical analysis done by SPSS 23, the independent t-tests, paired t-test, and ANOVA oneway were utilized for the association of continuous and nominal variables, respectively. Table 3.1. The American Society of Anesthesiologists classification of physical status $^{12}$

\begin{tabular}{|l|l|}
\hline ASA Classification & Definition \\
\hline ASA I & A normal healthy patient \\
\hline ASA II & A patient with mild systemic disease \\
\hline ASA III & A patient with severe systemic disease \\
\hline ASA IV & A patient with severe systemic disease that is a constant threat to life \\
\hline ASA V & A moribund patient who is not expected to survive without the operation \\
\hline ASA VI & A declared brain-dead patient whose organs are being removed for donor purposes \\
\hline
\end{tabular}




\section{Results}

The results obtained from the present study showed that the mean age of study sample was $29.86 \pm 16.77$ year. The percentages of the males and females were so comparable, $49.5 \%$ and $50.5 \%$, respectively. More than two-third of the patients $(75.5 \%)$ were aged 18 years or older and the remaining ones $(24.5 \%)$ were less than
18 years old, as shown in table 1 . The majority of the patients were located in ASA I (66.5\%) and ASA II (25.0\%). The mean of the operation duration was 50.32 \pm 26.83 minutes. The mean of the IV fluid injected into the patients with various operation types was 881.80 $\pm 526.91 \mathrm{~mL}$. In addition, the mean of pre and postoperation temperatures in the patients under study were $36.61 \pm 0.45{ }^{\circ} \mathrm{C}$ and $36.14 \pm 0.49{ }^{\circ} \mathrm{C}$, respectively.

Table 1: Baseline charactersictis of study patients

\begin{tabular}{|l|l|l|}
\hline \multirow{2}{*}{ Patients' Characteristics (n=200) } & Frequency Distribution & \\
\cline { 2 - 3 } & F & \\
\hline Gender & & 49.5 \\
Male & 99 & 50.5 \\
Female & 101 & \\
\hline Age Categories & & 75.5 \\
Adults ( $=>18$ years old) & 151 & 24.5 \\
Children (<18 years old) & 49 & 66.5 \\
\hline ASA physical status & 133 & 25.0 \\
I & 50 & 7.5 \\
II & 15 & 1.0 \\
III & 2 & 26.83 \\
IV & 50.32 & 526.91 \\
\hline Operation Duration, min & 881.80 & 0.45 \\
\hline IV Fluid (mL) & 36.61 & 0.49 \\
\hline Pre-Operation Temperature0C & 36.14 & \\
\hline Post-Operation Temperature0C & & \\
\hline
\end{tabular}

The incidence of post-operation core hypothermia was shown in table 2 . The study revealed that the overall core hypothermia in the study sample was $31.0 \%$ (mild hypothermia- 62 patients). This hypothermia was higher in males (34.3\%), adult patients (42.9\%), and those with duration of less than 2 hours (31.6\%).

Table 2: Incidence of hypothermia in study patients

\begin{tabular}{|l|l|l|}
\hline Patients' Categories & Frequency (F) & Percentage (\%) \\
\hline $\begin{array}{l}\text { Overall Hypothermia } \\
\text { temperature }<360 \mathrm{C} \text { (mild) }\end{array}$ & 62 & 31 \\
temperature $=>360 \mathrm{C}$ & 138 & 69 \\
\hline Gender & & \\
Male & 34 & \\
Hypothermia & 65 & 34.3 \\
Normothermia & 28 & 65.7 \\
Female & 73 & 27.7 \\
Hypothermia & & 72.3 \\
Normothermia & & \\
\hline
\end{tabular}


Cont... Table 2: Incidence of hypothermia in study patients

\begin{tabular}{|l|l|l|}
\hline Age Categories & & \\
Adults (=>18 year) & 41 & \\
Hypothermia & 110 & 42.9 \\
Normothermia & 21 & 57.1 \\
Pediatric (<18 year) & 28 & 27.2 \\
Hypothermia & & 72.8 \\
Normothermia & & \\
\hline Operation Duration & & \\
$<2$ hours (196 patients) & 62 & \\
Hypothermia & 134 & 31.6 \\
Normothermia & 0 & 68.4 \\
$\Rightarrow 2$ hours (4 patients) & 4 & 0.0 \\
Hypothermia & & 100 \\
Normothermia & \\
\hline
\end{tabular}

The core temperatures measured throughout the study duration in pre-operation and post-operation were compared by means of the statistical analyses as shown in table 3 . The study showed that the post-operative temperatures have been decreased, statistically significantly in all the patients under study and separately in adults, children, males, or females $(\mathrm{P}<0.00001)$.

Table 3: Comparison of pre and post-operation temperatures in study patients

\begin{tabular}{|c|c|c|c|}
\hline Categories & $\begin{array}{l}\text { Pre-operation Temperature } \\
\text { 0C } \\
\text { Mean } \pm \text { S.D. \& Range }\end{array}$ & $\begin{array}{l}\text { Post-operation } \\
\text { Temperature 0C } \\
\text { Mean } \pm \text { S.D. \& Range }\end{array}$ & p-value (two-sided) \\
\hline All patients $(n=200)$ & $\begin{array}{l}36.61 \pm 0.45 \\
34.30-37.60\end{array}$ & $\begin{array}{l}36.14 \pm 0.49 \\
34.30-37.20\end{array}$ & $\mathrm{P} \leq 0.001$ \\
\hline Adult Patients $(\mathrm{n}=151)$ & $\begin{array}{l}36.66 \pm 0.41 \\
35.20-37.60\end{array}$ & $\begin{array}{l}36.19 \pm 0.45 \\
35.10-37.20\end{array}$ & $\mathrm{P} \leq 0.001$ \\
\hline Children ( $\mathrm{n}=49)$ & $\begin{array}{l}36.47 \pm 0.53 \\
34.30-37.40\end{array}$ & $\begin{array}{l}36.01 \pm 0.59 \\
34.30-36.90\end{array}$ & $\mathrm{P} \leq 0.001$ \\
\hline Male Patients $(\mathrm{n}=99)$ & $\begin{array}{l}36.59 \pm 0.50 \\
34.30-37.60\end{array}$ & $\begin{array}{l}36.10 \pm 0.52 \\
34.30-37.10\end{array}$ & $\mathrm{P} \leq 0.001$ \\
\hline Female Patients $(\mathrm{n}=101)$ & $\begin{array}{l}36.63 \pm 0.40 \\
35.40-37.30\end{array}$ & $\begin{array}{l}36.18 \pm 0.46 \\
34.70-37.20\end{array}$ & $\mathrm{P} \leq 0.001$ \\
\hline
\end{tabular}

The post-operative core temperatures were compared between adults and children, in addition, between males and females and in order to understand to what extent the temperature has been reduced as compared to each other. The study showed a non-significant differences in the post-operative temperatures between adults and children $(p=0.059)$ between males and females $(p=0.256)$ and also between different ASA groups. Table 4. 
Table 4: Comparison of post-operation temperatures between adult and pediatric samples of the study

\begin{tabular}{|c|c|c|c|c|}
\hline \multicolumn{2}{|c|}{$\begin{array}{l}\text { Post-operation Temperature } \\
\text { (Adults) }\end{array}$} & \multicolumn{2}{|c|}{$\begin{array}{l}\text { Post-operation Temperature } \\
\text { (Children) }\end{array}$} & $\begin{array}{l}\text { p-value (two- } \\
\text { sided) }\end{array}$ \\
\hline \multicolumn{2}{|l|}{$36.19 \pm 0.45$} & \multicolumn{2}{|l|}{$36.01 \pm 0.59$} & $\mathrm{P}>0.05$ \\
\hline \multicolumn{2}{|c|}{$\begin{array}{l}\text { Post-operation Temperature } \\
\text { (Males) }\end{array}$} & \multicolumn{2}{|c|}{$\begin{array}{l}\text { Post-operation Temperature } \\
\text { (Females) }\end{array}$} & $\begin{array}{l}\mathrm{p} \text {-value (two- } \\
\text { sided) }\end{array}$ \\
\hline \multicolumn{2}{|l|}{$36.10 \pm 0.52$} & \multicolumn{2}{|l|}{$36.18 \pm 0.46$} & $\mathrm{P}>0.05$ \\
\hline $\begin{array}{l}\text { ASA I } \\
36.10(n=133)\end{array}$ & $\begin{array}{l}\text { ASA II } \\
36.24(n=50)\end{array}$ & $\begin{array}{l}\text { ASA III } \\
36.16(n=15)\end{array}$ & $\begin{array}{l}\text { ASA IV } \\
36.20(n=2)\end{array}$ & $\mathrm{P}>0.05$ \\
\hline
\end{tabular}

Table5 shows significant positive correlation between the age and post-operative temperature $(\mathrm{r}=0.160$, $\mathrm{p}=0.024)$. However, there was statistically not significant correlation between operation duration and post-operative temperature $(\mathrm{r}=0.56, \mathrm{p}=0.424)$.

Table 5: Person's correlation of post-operation temperature with patients' age and operation duration $(\mathrm{n}=\mathbf{2 0 0})$

\begin{tabular}{|l|l|l|}
\hline Characteristics & Post-Operative Temperature & p-value (two-sided) \\
\hline Patients' Age & $\mathrm{r}=0.160$ & $\mathrm{P} \leq 0.05$ \\
\hline Operation Duration* & $\mathrm{r}=0.056$ & $\mathrm{P}>0.05$ \\
\hline *the number of patients underwent surgery for $<120$ min were 96 ) and for $=>120$ min were 4. \\
\hline
\end{tabular}

Among study patients who underwent the operation, an univariate analysis was performed for the post-operation temperature as the dependent variables as shown in table 6 . The study revealed that the operation duration $(\mathrm{p}=0.045)$, and the pre-operative temperature $(\mathrm{p}=0.001)$ were predictors of hypothermia in our study sample.

Table 6: Univariate analysis of post-operation predictors in study patients underwent general anesthesia (Dependent Variable: Post Operation Temperature)

\begin{tabular}{|l|l|l|l|}
\hline Characteristics & $\begin{array}{l}\text { Degree of Freeedom } \\
(\mathbf{d f})\end{array}$ & F & p-value (two-sided) \\
\hline Age & 56 & 0.932 & $\mathrm{P}>0.05$ \\
\hline Sex & 1 & 0.732 & $\mathrm{P}>0.05$ \\
\hline ASA & 3 & 0.639 & $\mathrm{P}>0.05$ \\
\hline Operation Duration & 21 & 1.698 & $\mathrm{P}=0.045^{*}$ \\
\hline Pre-Operation Temperature & 22 & 8.591 & $\mathrm{P} \leq 0.001 *$ \\
\hline$*$ statistically significant level & & \\
\hline
\end{tabular}




\section{Discussion}

The incidence of inadvertent post-operative hypothermia among a Kurdish sample in Iraq was $31.0 \%$ with mild severity only also showed a significant reduction in the overall post-operative core temperature, with both genders, and different age categories so lower compared to other studies reported $57.8 \%$ hypothermia in 185 adult patients underwent scheduled emergency non-cardiac surgery in ICU admission ${ }^{13}, 44.8 \%$ hypothermia in operations of more than two hours 14 and $32 \%$ in another study ${ }^{15}$, study showed that male patients were more affected by hypothermia (34.3\%) compared to females (27.7\%) and adults (42.9\%) compared to pediatric patients $(27.2 \%)$. However, the overall differences of hypothermia between males and females $(p=0.059)$ and between adult and pediatric patients $(p=0.256)$ were not statistically significant. This reflects this reality that every person could be at risk of hypothermia. Although the elderly and very younger patients are more at risk of hypothermia ${ }^{16}$.

they reported that those with major-plus surgery, longer operation duration and $>2 \mathrm{~h}$, intravenous unarmed fluid infusion (>1000 ml) significantly are at risk of core hypothermia similar to study reported that those patients with elevated baseline core temperature prior to anesthesia) and high ambient temperature) are significantly lower at risk of core hypothermia ${ }^{15}$, we found there is a positive correlation between the operation duration and post-operative core temperature $(\mathrm{r}=0.056)$, but not significantly $(\mathrm{p}=0.429)$, possibly due to insufficient sub-sample size as those $=>120 \mathrm{~min}$ operation duration were only 4 patients which is in agreement with another study ${ }^{17}$ the patients with higher ASA physical status were more at risk of hypothermia ${ }^{2}$. In our study we could not find any significant correlation between post-operative hypothermia and different ASA physical status $(p=0.404)$. This may be attributed to small sample size in those with ASA III and ASA IV. According to the guidelines of the National Institute of Health and Clinical Excellence (NICE), it is necessary that in high-risk surgeries, perioperative temperature must be followed rigorously when the oral temperature is below $36^{\circ} \mathrm{C}$. Such patients must be warmed for 20 minutes before surgery commencement with convenient techniques ${ }^{18}$ and ${ }^{19}$ respectively.
Conclusions: The incidence of hypothermia in our study sample was not so high $(31.0 \%)$ defined as $=<36$ ${ }^{0} \mathrm{C}$.. A significant reduction in core body temperature of patients between pre and post-operation times was found $(\mathrm{P}<0.00001)$. Those patients with longer operation duration, lower room temperature, and lower preoperative temperature were more at risk of hypothermia.

\section{Ethical Clearance}

The Research Ethical Committee at scientific research by ethical approval of both environmental and health and higher education and scientific research ministries in Iraq; Also The ethical approval of the research was obtained from the local Health of the Ethics Committee of the General Directorate of Health in Duhok and Scientific Committee of College of Medicine-University of Duhok.

Conflict of Interest: The authors declare that they have no conflict of interest.

Funding: Self-funding

\section{References}

1. Díaz M, Becker DE. Thermoregulation: physiological and clinical considerations during sedation and general anesthesia. Anesth Prog. 2010; 57(1):25-34.

2. Belayneh T. Post-operative Hypothermia in Surgical Patients at University of Gondar Hospital, Ethiopia. J Anesth Clin Res. 2014. 05(10); 461465.

3. Kempainen, R. R. \& Brunette, D. D. The evaluation and management of accidental hypothermia. Respiratory care (2004). 49, 192-205

4. Stefanadis, C. et al. Heat production of atherosclerotic plaques and inflammation assessed by the acute phase proteins in acute coronary syndromes. Journal of Molecular and Cellular Cardiology (2000). 32, 43-52

5. Lenhardt, R. The effect of anesthesia on body temperature control. Frontiers in Bioscience Scholar (2010). 2S, 1145-1154

6. Swaminathan, A., Viswanathan, S., Gnanadurai, T., Ayyavoo, S. \& Manickam, T. Perceived stress and sources of stress among first-year medical undergraduate students in a private medical college - Tamil Nadu. National Journal of Physiology, 
Pharmacy and Pharmacology (2016). 6, 9-14

7. Samoila, G. et al. The Significance of Hypothermia in Abdominal Aortic Aneurysm Repair. Annals of Vascular Surgery (2017). 38, 323-331

8. Straub, A. et al. Platelet anaesthesia during extracorporeal circulation: Differential effects of GP IIb/IIIa blockers on platelet activation marker P-selectin expression at hypothermia. Thrombosis Research (2008). 122, 383-389

9. De Robertis, E. et al. Coagulopathy induced by acidosis, hypothermia and hypocalcaemia in severe bleeding. Minerva Anestesiologica (2015). 81, 6575

10. Chue AL, Moore RL, Cavey A, et al. Comparability of tympanic and oral mercury thermometers at high ambient temperatures. BMC Res Notes. 2012;5:356. Jul. (2012).

11. Childs, C., Harrison, R. \& Hodkinson, C. Tympanic membrane temperature as a measure of core temperature. Archives of Disease in Childhood (1999). 80, 262-266

12. Daabiss M. American Society of Anesthesiologists physical status classification. Indian J Anaesth . 2011. 55(2):111-115;

13. Abelha FJ, Castro MA, Neves AM, Landeiro NM, Santos CC. Hypothermia in a surgical intensive care unit. BMC Anesthesiol. 5:7; p 3-10; 2005.
14. Luís, C., Moreno, C., Silva, A., Páscoa, R. \& Abelha, F. Inadvertent Postoperative Hypothermia at Post-Anesthesia Care Unit: Incidence, Predictors and Outcome. Open Journal of Anesthesiology (2012). 02, 205-213

15. Yi, J., Zhan, L., Lei, Y. et al. Establishment and Validation of a Prediction Equation to Estimate Risk of Intraoperative Hypothermia in Patients Receiving General Anesthesia. Sci Rep (2017). 7, 13927

16. Mehta, O. H. \& Barclay, K. L. Perioperative hypothermia in patients undergoing major colorectal surgery. ANZ Journal of Surgery (2014). $84,550-555$

17. Guest, J. D., Vanni, S. \& Silbert, L. Mild hypothermia, blood loss and complications in elective spinal surgery. Spine Journal (2004). 4, 130-137

18. Reynolds, L., Beckmann, J. \& Kurz, A. Perioperative complications of hypothermia. Best Practice and Research: Clinical Anaesthesiology (2008). 22, 645-657

19. Butwick, A. J., Lipman, S. S. \& Carvalho, B. Intraoperative forced air-warming during cesarean delivery under spinal anesthesia does not prevent maternal hypothermia. Anesthesia and Analgesia (2007). 105, 1413-1419 